\title{
Aptamer-functionalized neural recording electrodes for the direct measurement of cocaine in vivo
}

\author{
I. Mitch Taylor ${ }^{1}$, Zhanhong Du ${ }^{1,2}$, Emma T. Bigelow ${ }^{3}$, James R. Eles ${ }^{1}$, Anthony R. Horner ${ }^{4}$, \\ Kasey A. Catt ${ }^{1}$, Stephen G. Weber ${ }^{4}$, Brian G. Jamieson ${ }^{3}$, and X. Tracy Cui ${ }^{1, *}$ \\ ${ }^{1}$ Department of Bioengineering, University of Pittsburgh, Pittsburgh, PA 15261, USA \\ ${ }^{2}$ Shenzhen Key Lab of Neuropsychiatric Modulation and Collaborative Innovation Center for Brain \\ Science, CAS Center for Excellence in Brain Science, Shenzhen Institute of Advanced \\ Technologies, Chinese Academy of Sciences, Shenzhen, 518055, China \\ ${ }^{3}$ Diagnostic Biochips, Glen Burnie, MD 21061, USA \\ ${ }^{4}$ Department of Chemistry, University of Pittsburgh, Pittsburgh, PA 15260, USA
}

\begin{abstract}
Cocaine is a highly addictive psychostimulant that acts through competitive inhibition of the dopamine transporter. In order to fully understand the region specific neuropathology of cocaine abuse and addiction, it is unequivocally necessary to develop cocaine sensing technology capable of directly measuring real-time cocaine transient events local to different brain regions throughout the pharmacokinetic time course of exposure. We have developed an electrochemical aptamerbased in vivo cocaine sensor on a silicon based neural recording probe platform capable of directly measuring cocaine from discrete brain locations using square wave voltammetry (SWV). The sensitivity of the sensor for cocaine follows a modified exponential Langmuir model relationship and complete aptamer-target binding occurs in $<2 \mathrm{sec}$ and unbinding in $<4 \mathrm{sec}$. The resulting temporal resolution is a $75 \mathrm{X}$ increase from traditional microdialysis sampling methods. When implanted in the rat dorsal striatum, the cocaine sensor exhibits stable SWV signal drift (modeled using a logarithmic exponential equation) and is capable of measuring real-time in vivo response to repeated local cocaine infusion as well as systemic IV cocaine injection. The in vivo sensor is capable of obtaining reproducible measurements over a period approaching 3 hours, after which signal amplitude significantly decreases likely due to tissue encapsulation. Finally, aptamer functionalized neural recording probes successfully detect spontaneous and evoked neural activity
\end{abstract}

*Corresponding author: 5057 Bioscience Tower 3, 3501 Fifth Ave. Pittsburgh, PA, 15260, USA. xic11@ pitt.edu. Phone: (412) 383-6672.

AUTHOR CONTRIBUTIONS

I.M.T. designed and carried out all cocaine sensing experiments, analyzed data and wrote the manuscript, Z.D. carried out the electrophysiological experiments, E.B. was involved in the initial project planning and optimized the gold coating and aptamer functionalization conditions in vitro, J.E. provided explant immunohistology and confocal imaging, A.H. and S.W. contributed by modeling calibration plots, K.C. assisted with the collection of scanning electron microscopy images, B.J. was involved in the project planning and oversaw the neural probe fabrication and X.T.C. was involved in the project planning, oversaw the experimental design, data analysis and manuscript writing. All authors have contributed in editing and revising the final manuscript.

I.M. Taylor, Z. Du, J.R. Eles, A.R. Horner, K.A. Catt, S.G. Weber and X.T. Cui have no conflicts of interest. During this study, E.T. Bigelow was the VP of research and development and B.G. Jamieson is the CTO at Diagnostic Biochips. Diagnostic Biochips has a potential to commercialize the technology. 
in the brain. This dual functionality makes the cocaine sensor a powerful tool capable of monitoring both biochemical and electrophysiological signals with high spatial and temporal resolution.

\section{Graphical abstract}

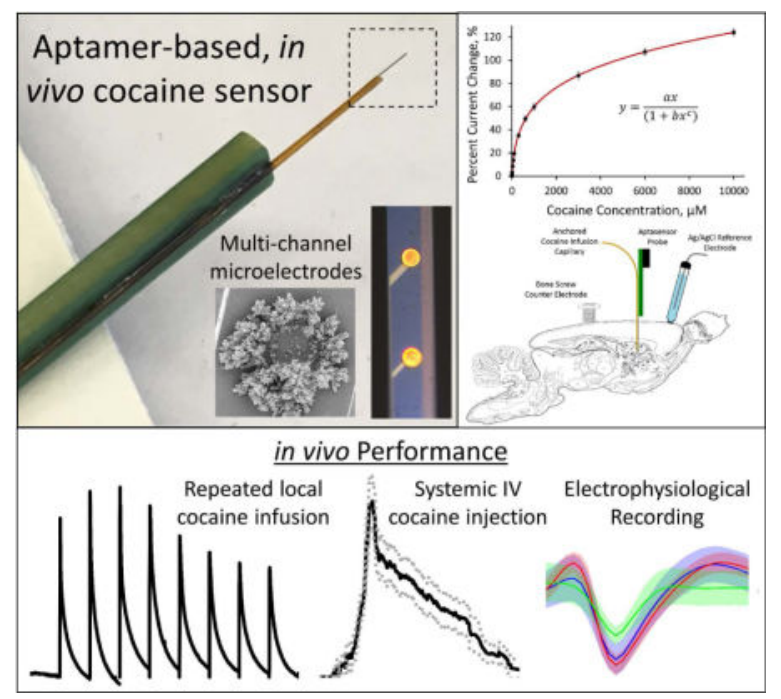

\section{Keywords}

cocaine; aptamer; neural recording probe; square wave voltammetry; in vivo; sensor

\section{INTRODUCTION}

Cocaine is a highly addictive psychostimulant that acts through competitive inhibition of the dopamine transporter ${ }^{1-6}$. Use and abuse of cocaine results in dependency and manifests as a significant financial and institutional burden on health care systems ${ }^{7}$. Understanding the real-time neuropathology of cocaine action in the brain is imperative to treating and preventing cocaine addiction. Cocaine activity throughout the brain is highly region specific $^{8-12}$ due to local variations in dopamine transporter and pre- and post-synaptic receptor expression ${ }^{3,5,13-18}$ as well as region-specific differences in local cocaine decomposition rates ${ }^{19}$. In order to fully understand the mechanism of cocaine action, it is unequivocally necessary to develop cocaine sensing technology with high spatial and temporal resolution that is capable of directly measuring real-time cocaine transient events in multiple discrete brain regions throughout the pharmacokinetic time course of exposure.

Real-time in vivo cocaine detection presents a unique analytical challenge. The technique must be selective for cocaine in the complex brain environment, exhibit high spatial and temporal resolution necessary to measure rapid in vivo fluctuations and maintain small physical dimensions to prevent damage of the delicate brain environment. Previous efforts to quantify in vivo cocaine have produced moderate success but exhibit poor spatial and temporal resolution. Bradberry et al. measured the pharmacokinetic time course of cocaine in the brain using microdialysis sampling techniques following intravenous (I.V.) cocaine 
injection ${ }^{20}$. This allowed for the selective detection of cocaine, but experimental limitations inherent to microdialysis sampling result in a temporal resolution of approximately 5 minutes and spatial averaging over the entire $0.0314 \mathrm{~mm}^{3}$ volume of the sampling probe. In addition, it is well characterized that the insertion of a microdialysis probe into the brain results in widespread tissue damage, which leads to a significant decrease in extraction efficiency. Decreased extraction efficiency can in turn lead to an underestimation of reported in vivo analyte concentration ${ }^{21-25}$. Cocaine has also been monitored in the brain through analysis of postmortem digested tissue content at various time-points following cocaine introduction ${ }^{19,26}$. The analysis is selective, but the temporal resolution is inherently poor due to the detection of a single time-point per animal and the spatial resolution is limited by the physical size of the excised tissue. The present study details the development, optimization and in vivo use of a cocaine sensor that overcomes these analytical challenges.

Aptamers are highly customizable single-stranded DNA (or RNA) fragments that selectively bind a specific target, ranging from small molecules to large proteins ${ }^{27}$. Target binding commonly results in the aptamer trapping the target molecule by undergoing a reversible three dimensional conformational change based on the binding affinity of the target to the aptamer ${ }^{27}$. This reversibility ensures that analyte is not consumed or adsorbed in the process $^{28}$. The customizability of aptamer synthesis allows for the incorporation of functional groups, necessary to undergo covalent attachment, as well as reporter molecules, capable of monitoring target binding ${ }^{29}$. Aptamers are commonly functionalized with electrochemical reporter molecules, such as methylene blue (MB), ferrocene and anthraquinone to allow for the direct detection of analyte binding through electrochemical techniques ${ }^{29}$. In fact, electrochemically monitored aptamer sensors have been developed for a wide array of targets, ranging from small molecules (cocaine, doxorubicin, tobramycin and ATP) $)^{30-35}$ to large biomolecules (i.e. thrombin, PDGF and gene 32 protein) $)^{36-42}$. This study makes use of a MB functionalized cocaine-targeting aptamer ${ }^{30-32}$ for the electrochemical detection of cocaine.

Implantable silicon-based neural recording probes allow for the direct measurement of electrophysiological signals from individual neuron groupings with high-quality, single cell resolution ${ }^{43}$. Information obtained from neural recording probes are highly intriguing due to the broad clinical and research applications afforded by the technology 43,44 .

Microfabrication techniques allow for nearly limitless customizability of electrode material, spacing and design of silicon-based neural recording probes. While the use of multichannel neural recording probes to measure electrophysiological activity is well characterized, the transition of the technology to a biochemical sensing platform is still at its infancy stage. Here we detail the successful development and use of an electrochemical aptamer-based cocaine sensor, pattered on a silicon-based neural recording probe substrate, capable of directly measuring cocaine with high spatial and temporal resolution in vivo.

\section{EXPERIMENTAL}

\section{Materials}

All chemicals and reagents were purchased from Sigma Aldrich (St. Louis, MO, USA). All solutions were prepared using DNase free water and PBS to promote aptamer stability. 
Cocaine-targeting aptamer, $5^{\prime}$-HS- $\left(\mathrm{CH}_{2}\right)_{6}$ -

AGACAAGGAAAATCCTTCAATGAAGTGGGTCG- $\left(\mathrm{CH}_{2}\right)_{7}-\mathrm{MB}-3^{\prime},{ }^{30,}, 32$ was designed with a $5^{\prime}$ terminal thiol group (attached with a six carbon linker) to facilitate direct covalent linkage to the gold surface and a $3^{\prime}$ terminal methylene blue (MB) group (attached with a seven carbon linker) as an electrochemical reporter molecule. Aptamer was synthesized and dual HPLC purified prior to purchase from Biosearch Technologies, Inc. (Novato, CA, USA). This specific cocaine-targeting aptamer has been well characterized to exhibit a 90 $\mu \mathrm{M} K_{d}^{30}$. Neural recording probes were fabricated and provided by Diagnostic Biochips (Glen Burnie, MD, USA). For direct local cocaine infusion experiments, neural recording probes were manufactured with a fused silica capillary $(75 \mu \mathrm{m}$ i.d., $180 \mu \mathrm{m}$ o.d., Polymicro Technologies, Phoenix, AZ, USA) anchored directly to the PCB such that the capillary is positioned on the underside of the silicon probe shank with the capillary outlet located directly adjacent to the $14^{\text {th }}$ electrode site from the tip ( $2.6 \mathrm{~mm}$ from the tip). Representative images and schematic drawings of the capillary modified neural recording probe are provided in Figures 1a and 1b. The capillary inlet was thread into the barrel of a 22 gauge gastight syringe needle (Hamilton Co., Reno, NV, USA) and anchored with five minute epoxy (ITW Devcon, Danvers, MA, USA). Cocaine was delivered through the capillary via manual depression of a $10 \mu \mathrm{L}$ gastight syringe (Hamilton Co., Reno, NV, USA).

\section{Electrochemical Methods}

All electrochemical procedures were conducted using a three-electrode design (working electrode: individual neural recording probe electrodes; reference electrode: $\mathrm{Ag} / \mathrm{AgCl}$; counter electrode: platinum sheet (in vitro experiments) or stainless steel bone screw (in vivo experiments)). The Gamry potentiostat, FAS2 femtostat (Gamry Instruments, Warminster, PA, USA) was used for all cyclic voltammetry and multi-step chronoamperometry procedures and the Autolab potentiostat/galvanostat, PGSTAT128N (Metrohm, Herisau, Switzerland) was used for all square wave voltammetry (SWV) procedures (in vivo and in vitro).

\section{Aptamer-based cocaine sensor fabrication}

Cocaine sensors were developed using single shank, silicon neural recording probes (90 $\mu \mathrm{m}$ $\times 15 \mu \mathrm{m} \times 7 \mathrm{~mm}$ ) with 16 individual $37 \mu \mathrm{m}$ diameter gold electrode recording sites (see Figure 1a) centered and equally spaced along the silicon shank at $200 \mu \mathrm{m}$ increments ( $3 \mathrm{~mm}$ total electrode spacing) as a substrate. Probes are fabricated with the deposition of dielectric material on silicon wafers, followed by patterning of metal traces and deposition of a second dielectric stack over the metal. Contact vias are etched in the recording site and bondpad areas to the metal traces below, which connect sites and pads. Gold recording sites and gold bondpads are deposited by e-beam evaporation, and patterned with liftoff. Each probe is flip chip bonded to a custom rigid circuit board with 40-pin Samtec connector for readout ${ }^{45}$. Each electrode site was electrochemically cleaned via repeat cyclic voltammetry cycling in $\mathrm{H}_{2} \mathrm{SO}_{4}(-350 \mathrm{mV}$ to $1.5 \mathrm{~V}$ at $1 \mathrm{~V} / \mathrm{sec}, 25$ cycles) and individually coated with dendritic gold (see Figures $2 \mathrm{~b}, \mathrm{c}$ ) via repeat multi-step chronoamperometry $(-400 \mathrm{mV}$ for $1 \mathrm{sec}$ followed by $0 \mathrm{~V}$ for $1.5 \mathrm{sec}, 240$ cycles) in a stirred solution containing $3.5 \mathrm{M} \mathrm{HAuCl}_{4}$ and $0.1 \mathrm{M} \mathrm{NaCl}$ in $1.5 \% \mathrm{wt} \mathrm{HCl} 35,46$ to increase the available gold surface area. Dendritic gold coated electrodes were immediately functionalized with cocaine-targeting aptamer using well- 
established protocols ${ }^{47} .5 \mu \mathrm{L}$ aliquots of $100 \mu \mathrm{M}$ aptamer solution were incubated in $10 \mu \mathrm{L}$ of $50 \mathrm{mM}$ tris-(2-carboxyethyl) phosphine hydrochloride (TCEP, prepared in water) for 1 hour to reduce the $5^{\prime}$ thiol group for gold attachment ${ }^{47}$. Reduced aptamer solution was then diluted to $5 \mu \mathrm{M}$ with PBS for electrode functionalization. Dendritic gold-coated neural recording probes were functionalized by overnight incubation in aptamer solution. Finally, functionalized electrodes were soaked in $30 \mathrm{mM}$ 6-mercaptohexanol $\mathrm{MCH}$, prepared in water) for 5 hours to block any unreacted gold surface ${ }^{31,47,48}$. The resulting cocaine sensing probes were rinsed and stored in a dark, dry environment until use (maximum 3 days).

\section{In vitro calibrations}

All in vitro experiments were conducted in artificial cerebral spinal fluid (aCSF: $142 \mathrm{mM}$ $\mathrm{NaCl}, 1.2 \mathrm{mM} \mathrm{CaCl}_{2}, 2.7 \mathrm{mM} \mathrm{KCl}, 1.0 \mathrm{mM} \mathrm{MgCl}_{2}, 2.0 \mathrm{mM} \mathrm{NaH}_{2} \mathrm{PO}_{4}, \mathrm{pH} 7.4$ ) using cocaine hydrochloride. Detection at the aptamer-based cocaine sensor was performed using SWV. SWV potential was swept from $-150 \mathrm{mV}$ to $-550 \mathrm{mV}$ at $100 \mathrm{~Hz}$ with a $-5 \mathrm{mV}$ step height and a $25 \mathrm{mV}$ pulse height. Each SWV waveform produced a single redox peak located at $-300 \mathrm{mV}$, resulting from the redox activity of MB. In vitro calibration experiments were performed via repeated cocaine spiking into a single $2 \mathrm{~mL}$ aCSF solution. A single SWV scan was applied in aCSF and at 3 cocaine concentrations per decade from $1 \mu \mathrm{M}$ to 10 $\mathrm{mM}$. The percent current change, determined via comparison to the baseline peak current, was plotted versus concentration as a calibration plot. Calibration plots were fit using a modified exponential Langmuir model. The resulting parameters were used as calibration factors to convert unknown percent current change to concentration. Repeat in vitro cocaine infusion experiments were conducted using a custom built, syringe-pump fed (Fisher Scientific, Pittsburgh, PA, USA) flow cell. The flow cell consisted of an air-actuated 6-port valve (Valco Instruments Co. Inc., Houston, TX, USA) controlling a sample injection port, $150 \mu \mathrm{L}$ sample loop, waste port, aCSF introduction port and a flow-through detection channel. Flow rate was held at a constant $1 \mathrm{~mL} / \mathrm{min}$. $500 \mu \mathrm{M}$ cocaine was repeatedly infused over the electrode for $5 \mathrm{sec}$ every $45 \mathrm{sec}$. For all flow cell experiments, SWV measurements were repeated every 2 seconds (the maximum frequency allowed by the potentiostat at the assigned SWV waveform parameters). Interferent experiments were conducted using 100 $\mu \mathrm{M}$ solutions of cocaine, L-glutamic acid, $\gamma$-aminobutyric acid (GABA), D-(+)-glucose, dopamine hydrochloride and L-ascorbic acid prepared in DNase free PBS. In vitro stability testing was conducted over five hours in PBS. SWV measurements were collected every 2 seconds (as detailed above) for the entire duration. Measurements were recorded in a $1 \mathrm{mM}$ cocaine solution at 1 hour intervals to determine sensor longevity. Percent current change values were determined based on baseline SWV peak height obtained in PBS immediately prior to each cocaine test.

\section{In vivo procedures}

All animal procedures were approved by the University of Pittsburgh Institutional Animal Care and Use Committee. For all in vivo experiments, male Sprague Dawley (SD) rats (250$359 \mathrm{~g}$ : Charles River, Ashland, OH, USA) were anesthetized with isoflurane (2\% by volume) and were immobilized in a stereotaxic frame with the incisor bar raised to $5 \mathrm{~mm}$ above the interaural line ${ }^{49}$. Body temperature was maintained at $37^{\circ} \mathrm{C}$ using a Deltaphase 
isothermal pad (Braintree Scientific Inc., Braintree, MA, USA). Portions of the skull and dura were removed directly above the dorsal striatum ( $2.5 \mathrm{~mm}$ anterior to bregma, $2.5 \mathrm{~mm}$ lateral from bregma) to allow insertion of the neural recording probe cocaine sensor into the dorsal striatum ( $5 \mathrm{~mm}$ below the cortical surface) as well as in two other unmeasured positions in the contralateral hemisphere for the placement of a stainless steel counter electrode bone screw and a $\mathrm{Ag} / \mathrm{AgCl}$ reference electrode (connected via salt bridge). In vivo electrode placement is further detailed in Figures $1 \mathrm{c}$ and $1 \mathrm{~d}$.

For each animal, the SWV waveform was applied immediately upon insertion of the cocaine sensor and was repeated every 2 seconds (the maximum frequency allowed by the potentiostat at the assigned SWV waveform parameters) until the predetermined experimental endpoint. Electrodes were allowed to stabilize in vivo for 30 minutes prior to data collection. Following the stabilization period, baseline in vivo electrode drift was monitored for 30 minutes. At this point cocaine was administered to all animals. The SWV peak amplitude measured immediately prior to cocaine administration was used for in vivo percent current change calculations. For single challenge direct local cocaine infusion experiments, a $1 \mu \mathrm{L}$ bolus of a $250 \mathrm{mM}$ cocaine solution was directly infused into the brain through the anchored fused silica capillary and the subsequent response was monitored for $30 \mathrm{~min}$. For repeated direct local cocaine infusion experiments, $1 \mu \mathrm{L}$ boluses of a $250 \mathrm{mM}$ cocaine solution were directly infused into the brain through the fused silica capillary every $30 \mathrm{~min}$ for four hours. For intravenous (I.V.) injection experiments, $2 \mathrm{mg} / \mathrm{kg}$ cocaine was delivered into the lateral tail vein and the response was monitored for $60 \mathrm{~min}$. Upon the predetermined experimental endpoint, animals were humanely sacrificed via injection of 2 $\mathrm{mEq}$ of potassium chloride directly into the heart followed by cervical dislocation. Explanted probes were fixed in 4\% paraformaldehyde for 30 minutes and then stored in PBS until scanning electron microscopy imaging.

For in vivo electrophysiological recording, a single SD rat was anesthetized under $2 \%$ Isoflurane and head-fixed in a SR-6R stereotaxic frame (Narishige, NY). A $2 \mathrm{~mm}$ by $2 \mathrm{~mm}$ craniotomy was preformed above the right somatosensory barrel cortex (SI) and centered at coordinates of $2.5 \mathrm{~mm}$ posterior to bregma and $5.5 \mathrm{~mm}$ lateral to midline $\mathrm{e}^{50}$. Dura mater was carefully pierced with a bent needle and recessed. The aptamer functionalized neural recording probe was inserted into the cortex with a micromanipulator to at a depth of 950 $\mu \mathrm{m}$ beneath the cortical surface corresponding to deep layer IV. The neural signal was amplified with a 16 channel Medusa preamplifier and recorded with an RX5 processor at 25 kHz sampling rate (Tucker-Davis Technologies, FL). Neural signal was subsequently processed with custom MATLAB scripts. The contralateral facial whisker was stimulated by a mechanical relay-based whisker stimulator controlled by $5 \mathrm{~V}$ transistor-transistor logic TTL) signals of RX5 digital output ${ }^{51}$. Whisker stimulation is consisted of a single TTL trigger of $100 \mathrm{~ms}$ duration and was delivered every 1.5 seconds for 60 replicates.

\section{Data analysis}

SWV data was analyzed using MATLAB (MathWorks Inc., Natick, MA, USA) and Microsoft Excel (Microsoft Corp., Redmond, WA, USA). Raw SWV curves were filtered through a third order Butterworth filter with the cutoff frequency set to $3 \mathrm{~dB}$ below a 0.15 
normalized frequency unit bandpass value. Statistical analyses were conducted using IBM SPSS software (v22, IBM Corm, Armonk, NY, USA). All in vivo percent current change responses are normalized to the final baseline SWV peak height prior to cocaine introduction and are presented as baseline subtracted plots, unless otherwise noted. Modified exponential Langmuir fitting was performed using the Curve Fitting Tool application in MATLAB. This toolset calculates the sum of squares due to error, R-square, adjusted Rsquare, and root mean squared error to determine the optimal set of parameters. Percent current change was converted to cocaine concentration using a numeric solver, 'vpasolve' function, in MATLAB. Percent current change values below the calculated lower limit of detection were assigned a zero cocaine concentration.

The raw neural recording data was filtered through a second order Butterworth filter between $300 \mathrm{~Hz}$ and $3000 \mathrm{~Hz}$ for spike analysis. Baseline fluctuations caused by the whisker stimulator and animal movement were removed by the Subtraction of Artefacts by Local Polynomial Approximation (SALPA) algorithm ${ }^{52}$. The spikes detected offline with a 3.5 standard deviation threshold ${ }^{53}$. The K-means method was subsequently applied to precluster the detected threshold-crossing events on each channel, yielding a large number of plausible units, next the small clusters were aggregated by a mixture of multivariate tdistribution algorithms ${ }^{54}$.

\section{Scanning electron microscopy}

Individual electrode sites from neural recording probes either before or after in vivo implantation were imaged using scanning electron microscopy. Images were collected at the University of Pittsburgh Center for Biological Imaging using a JSM6330 scanning electron microscope (Jeol, Peabody, MA, USA). The silicon shanks were removed from the printed circuit board connector, mounted to the stage and grounded using conductive copper tape for imaging. 1000X and 15000X magnification images were collected under vacuum using a 3 $\mathrm{kV}$ acceleration voltage and a working distance automatically adjusted for optimal image quality.

\section{Staining and confocal imaging of explanted devices}

Following removal from the brain, implants were gently washed with PBS and soaked in 4\% paraformaldehyde for 1 hour. The implants were then stained to label nuclei (1:1000 Hoescht 33342, Invitrogen, Carlsbad, CA, USA), microglia (1:500 IBA-1 antibody, rabbit, Wako Pure Chemical Industries, Ltd., Richmond, VA, USA; 1: 500 Alexa Fluor 488 goat anti-rabbit IgG, Invitrogen), and IgG plasma protein (1:500 Alexa Fluor 633 goat anti-rat $\operatorname{IgG}(\mathrm{H}+\mathrm{L})$, Invitrogen) as previously described ${ }^{55}$. Confocal imaging of implants was performed with an Olympus Fluoview 1000 confocal scanning microscope (Olympus Corporation, Tokyo, Japan) with a 20X objective.

\section{RESULTS AND DISCUSSION}

\section{Aptamer-based cocaine sensor development}

An electrochemical aptamer-based cocaine sensor was developed on a 16-channel, single shank silicon-based neural recording probe. Multichannel neural recording probes, 
traditionally used for electrophysiological neural recording purposes, were chosen as the optimal substrate for this sensor due to many factors ideally suited for in vivo cocaine detection. Each individual $37 \mu \mathrm{m}$ diameter gold electrode site (scanning electron microscopy image shown in Figure 2a) is a highly conductive, isolated recording location that allows for rapid electrochemical measurement (second to sub-second temporal resolution).

Additionally, the $200 \mu \mathrm{m}$ electrode spacing allows for multiplexed measurement from several, spatially discrete regions of the brain. The dimensions of the silicon shank ( $90 \mu \mathrm{m} \times$ $15 \mu \mathrm{m} \times 7 \mathrm{~mm})$ are much smaller than a typical microdialysis probe $(200 \mu \mathrm{m}$ O.D. $\times 1 \mathrm{~mm})$ and have been shown to elicit significantly less immune response upon brain implantation ${ }^{56}$. In fact, chronically implanted neural recording probes are routinely capable of collecting electrophysiological recording data with high signal integrity for periods exceeding 3 months following in vivo implantation ${ }^{57}$. As a whole, neural recording probes provide excellent spatial and temporal resolution and are a minimally invasive implant design.

As in previous aptamer sensor work $^{35}$, each individual gold electrode site (Figure 2a) was electrodeposited with a dendritic gold layer ${ }^{46}$ (low and high magnification scanning electron microscopy images shown in Figures $2 \mathrm{~b}$ and $2 \mathrm{c}$ respectively) via repeated multistep chronoamperometry ${ }^{35}$. The majority of the dendritic gold was localized to the edges of the electrode surface, indicating that the electrode surface exhibits "edge effect" behavior typical of microelectrodes ${ }^{58}$. Dendritic gold deposition serves to incorporate a reactive surface for self-assembled monolayer (SAM) aptamer functionalization while increasing the overall electrode surface area and decreasing the overall electrode impedance. Comparison of average electrode impedance before and after dendritic gold coating (Figure 2d, \pm SEM) reveals a general impedance drop over all frequencies measured. The dendritic gold coated electrode sites then underwent thiol-mediated SAM aptamer functionalization and 6mercapto-1-hexanol (MCH) blocking ${ }^{47}$. The 32-base pair cocaine-targeting aptamer was synthesized with a 5' C6-thiol terminus, to facilitate covalent SAM attachment to the gold electrode surface, and a 3' C7-methylene blue (MB) terminus, to allow for efficient, electrochemical monitoring of aptamer folding state. The MB group undergoes distance dependent electron transfer between the aptamer and the electrode surface upon electrochemically induced reversible MB reduction. In the unbound state, the anchored cocaine-targeting aptamer is in its partially folded, extended state with one hairpin loop whereas upon cocaine binding the aptamer assumes its fully folded, compact state with two hairpin loops ${ }^{59}$. This cocaine induced folding has the effect of bringing the electron donating MB group (located on the non-anchored 3' end) closer to the gold electrode surface, thus facilitating electron transfer between MB and the electrode and increasing the amplitude of the MB peak redox current. MCH blocking following aptamer attachment is a wellestablished method of passivating unreacted gold surfaces to prevent additional gold crossreactivity and to facilitate vertical aptamer alignment ${ }^{31,47,48}$. Impedance testing following aptamer immobilization (Figure 2d) revealed a slight increase in total electrode impedance at frequencies below $10000 \mathrm{~Hz}$. The average $1 \mathrm{kHz}$ impedance, relevant to electrophysiological recording, is significantly altered by both dendritic gold deposition and aptamer functionalization (repeated measures ANOVA, $\mathrm{F}(2,18)=368, \mathrm{p}<2 \mathrm{E}^{-8}$, Bonferroni post hoc comparison, $\mathrm{p}<0.05)$. Regardless of the significant increase in $1 \mathrm{kHz}$ impedance following aptamer functionalization, the dendritic gold coated, aptamer functionalized electrode 
remains highly conductive (14X lower impedance than uncoated gold electrodes) and is deemed suitable as an electrochemical sensor.

The average baseline square wave voltammetry (SWV) response elicited from aptamer functionalized electrode sites with (Figure 2e, blue line) and without (red line) dendritic gold deposition in aCSF each display a single SWV peak resulting from the electron transfer between the unbound, extended state aptamer and the electrode surface. Dendritic gold coated electrode sites exhibit increased SWV peak current compared to bare electrodes, indicating an increase in immobilized aptamer on dendritic coated electrodes ${ }^{35,60}$. This finding was expected since dendritic gold deposition increased the effective electrode surface area for aptamer attachment and lowered overall electrode impedance. Finally, the tight SEM error bars for the baseline SWV response confirms that the aptamer MEA sensor fabrication process is highly reproducible.

\section{In vitro detection of cocaine}

The aptamer functionalized cocaine sensor is sensitive and selective (selectivity over common neurochemical interferents are detailed in Supplementary Figure 1) for the electrochemical detection of cocaine using SWV. The average MB-induced SWV peak current increases with cocaine concentration in aCSF (Figure 3a) with the percent current change versus cocaine concentration calibration plot following a "hyperbolic profile" 30,32 (Figure $3 b$ ). As in previous studies ${ }^{30,32}$, the SWV response is represented by percent current change, obtained by normalizing to the baseline SWV peak current, to account for probe-toprobe variations in electrode surface area and aptamer density. The calibration plot obtained from each individual electrode was fit using the modified exponential Langmuir model described in Equation $1^{61}$.

$$
y=\frac{a x}{\left(1+b x^{c}\right)} \quad \text { Equation } 1
$$

For example, the average calibration plot displayed in Figure $3 \mathrm{~b}$ was modeled using the following parameters: $\mathrm{a}=0.3771, \mathrm{~b}=0.03107, \mathrm{c}=0.744$. These parameters serve to relate percent current change to cocaine concentration (micromolar). Prior to determining the optimal equation, attempts were made to fit the response using traditional Langmuir (as performed in previous aptamer sensor studies ${ }^{33}$ ) and Freundlich isotherms as well as twoand three-site Langmuir models and a variety of modified Langmuir models that include the effects of analyte concentration ${ }^{61}$. None of these equations produced the quality of fit observed by the modified exponential Langmuir model (Figure 3b), as determined by the magnitude and pattern of the residuals. The modified exponential Langmuir equation successfully models the linear portion of the calibration response observed over the first 100 $\mu \mathrm{M}$ while producing high quality fit to the curvature at higher concentrations. Obtaining a high quality fit throughout the entire cocaine calibration response is absolutely critical to maintaining accuracy and ensuring proper conversion of unknown percent current response to cocaine concentration over four orders of concentration magnitude. The modified exponential Langmuir model provides a superior fit to the electrochemical aptamer based 
sensor response and serves as a significant advancement from current Langmuir modeling conventions.

As shown in previous studies ${ }^{32,33}$, cocaine detection by aptamer based sensors is reversible. Using a custom-built air-actuated flow cell designed to directly perfuse aCSF solutions of varying cocaine concentration over the aptamer functionalized electrode sites, we repeatedly introduced 5 second boluses of $500 \mu \mathrm{M}$ cocaine onto the probe every 45 seconds. The resulting percent current change response to repeat cocaine introduction was converted to cocaine concentration using the aforementioned modified exponential Langmuir calibration plot model (Figure $3 \mathrm{~b})$ and plotted $( \pm$ SEM) in Figure $3 \mathrm{c}$. The cocaine sensor successfully measured the repeat exposure of $500 \mu \mathrm{M}$ cocaine over the $5 \mathrm{sec}$ duration of cocaine exposure ( 2 data points per infusion). This not only highlights the excellent reproducibility of the cocaine sensor, but also demonstrates the effectiveness of the newly designed calibration model for the conversion of unknown percent current change to cocaine concentration. Overlaying the average responses to each of the repeated $500 \mu \mathrm{M}$ cocaine exposures (Figure $3 \mathrm{~d}$, SEM removed for clarity) reveals the temporal resolution of the cocaine sensor. The sensor on average repeatedly reaches maximum signal (>80\%) in $2 \mathrm{sec}$ or less ( $2 \mathrm{sec}$ is the maximum temporal resolution of the $100 \mathrm{~Hz} \mathrm{SWV}$ data collection at these parameters) and reaches minimum signal $(<20 \%)$ in $4 \mathrm{sec}$ or less. These durations directly correlate to the rates of cocaine-aptamer binding and unbinding upon cocaine introduction and removal respectively in aCSF. This single-second temporal resolution is sufficient to observe rapid in vivo cocaine fluctuations and serves as a marked improvement over the $\sim 5$ min temporal resolution typical of microdialysis sampling techniques ${ }^{20}$. Direct comparison between the aptamer-based cocaine sensor and microdialysis sampling techniques reveals a $75 \mathrm{x}$ improvement in temporal resolution afforded by the aptamer sensor.

It should be noted that the in vitro detection of cocaine results in a right-shift in SWV peak potential (more positive) at higher concentrations. This peak shifting phenomenon has previously been shown ${ }^{32}$, and is likely due to a decrease in local $\mathrm{pH}$ caused by the introduction of cocaine hydrochloride salt into the aCSF solution. Similar right-shifts in peak potential were also observed upon introduction of glutamic acid and ascorbic acid during interferent testing experiments (Supplementary Figure 1).

\section{In vivo detection of direct local cocaine infusion}

The in vivo effectiveness of the cocaine sensor was initially determined through direct local cocaine infusion experiments using a neural recording probe manufactured with a $180 \mu \mathrm{m}$ o.d. fused silica capillary directly anchored onto the silicon substrate to allow controlled cocaine delivery to the environment directly surrounding the probe (Figure 1a). In these initial experiments, only electrodes located directly adjacent to the capillary outlet (less than $200 \mu \mathrm{m}$ from the outlet) were functionalized with cocaine aptamer (Figure 1b, red). These sites were chosen to show the effect of a direct local cocaine delivery to the immediate vicinity of the cocaine sensing electrode. For each experiment, a single capillary anchored, aptamer functionalized neural recording probe was implanted into the dorsal striatum of isoflurane anesthetized rats. Electrical connection was established via a contralaterally implanted counter electrode bone screw and a $\mathrm{Ag} / \mathrm{AgCl}$ reference electrode placed in contact 
with the meninges via salt bridge connection (Figures 1c,d). The $100 \mathrm{~Hz}$ SWV potential waveform was applied immediately upon probe implantation and was repeated at a maximum collection frequency of $2 \mathrm{sec}$. The electrode was allowed to stabilize for 30 minutes prior to data collection. Upon completion of the electrode stabilization period, the baseline drift was monitored for $30 \mathrm{~min}$, a single $1 \mu \mathrm{L}$ bolus of $250 \mathrm{mM}$ cocaine was infused and the subsequent response was further monitored for an additional $30 \mathrm{~min}$. The average percent current change response (SEM removed for clarity) from $n=5$ individual rats (Figure 4a) reveals that electrodes exhibit a reproducible baseline drift prior to a robust percent current change increase and subsequent diffusive decay upon the introduction of the cocaine bolus at $\mathrm{t}=30 \mathrm{~min}$. Percent current change calculations were determined using the SWV peak amplitude measured immediately prior to cocaine infusion. These findings unequivocally confirm the effectiveness of the aptamer functionalized cocaine sensor for the in vivo detection of cocaine. This represents the first sensor technology capable of directly measuring transient cocaine concentration in the brain. In addition, this response confirms the stability and continued functional activity of single-stranded DNA aptamer in the complex, DNase-rich brain environment, thus opening the door to widespread aptamer based in vivo sensing.

As previously detailed, the cocaine sensor exhibits a reproducible drift in percent current change response in vivo (Figure 4a, initial $30 \mathrm{~min}$ ). This decay is observed in all animals and directly corresponds with a right-shift in SWV peak potential (more positive potential, Figure 4a inset). Cocaine infusion resulted in a further, substantial right-shift in SWV peak potential (Figure $4 \mathrm{a}$ inset). The possible causes and resulting implications of this baseline drift will be detailed later in this manuscript. The initial baseline drift follows a logarithmic exponential decay with high regression fit correlation $\left(\mathrm{r}^{2}>0.98\right)$. This regression equation serves to quantify the rate of in vivo electrode drift and provides a means for mathematical drift subtraction. Due to the high correlation of the regression fit for the initial $30 \mathrm{~min}$ baseline drift, we made the assumption that the in vivo electrode drift will continue to decay according to the same logarithmic exponential relationship. This assumption allows for the mathematical subtraction of the electrode drift equation at each data collection time point for the entire $60+\min$ in vivo response. Figure $4 \mathrm{~b}$ represents the average baseline subtracted percent current change response (SEM removed for clarity) to direct local cocaine infusion from electrode sites located within $200 \mu \mathrm{m}$ of the capillary outlet ( $\mathrm{n}=5$, average unsubtracted response shown in Figure 4a). Direct comparison of the average percent current response before (Figure 4a) and after (Figure 4b) baseline subtraction clearly reveals the effectiveness of the mathematical drift subtraction technique. The average baseline subtracted response exhibits a flat initial baseline ( $0-30 \mathrm{~min})$, an immediate percent current change response to cocaine infusion at $\mathrm{t}=30 \mathrm{~min}$ and a subsequent asymptotic return to baseline resulting from analyte diffusion in the following $30 \mathrm{~min}$. This baseline subtraction has the effect of removing the non-cocaine related signal drift from the response and allowing for the direct quantification of transient in vivo cocaine activity alone. All subsequent in vivo cocaine sensing data presented in this study will be presented as baseline subtracted plots.

The use of a 16-channel, single shank silicon neural recording probe (each electrode site separated by $200 \mu \mathrm{m}$ ) as a sensor substrate allows for excellent spatial resolution. Aptamer functionalized electrode sites located greater than $1.8 \mathrm{~mm}$ from the capillary outlet (Figure 
$1 b$, blue) exhibited minimal average ( \pm SEM, $n=5$ ) percent current response to a single $1 \mu \mathrm{L}$ bolus of $250 \mathrm{mM}$ cocaine at $\mathrm{t}=0 \mathrm{~min}$ (Figure $4 \mathrm{c}$, blue), whereas electrode sites located within $200 \mu \mathrm{m}$ of the capillary outlet (Figure $1 \mathrm{~b}$, red) exhibit a robust average $(( \pm$ SEM, $\mathrm{n}=5)$ response to cocaine infusion (red, same response displayed in Figure $4 \mathrm{~b}$ with an adjusted time axis) and no quantifiable average percent current change response to a single $1 \mu \mathrm{L}$ PBS infusion at $\mathrm{t}=0 \mathrm{~min}$ (green, $\mathrm{n}=2$ ). This spatial resolution is further demonstrated following the conversion of percent current change to cocaine concentration (Figure 4d). Electrode sites located within $200 \mu \mathrm{m}$ of the capillary outlet exhibited a $4.0 \pm 0.9 \mathrm{mM}(4000 \pm 900$ $\mu \mathrm{M})$ average maximum cocaine signal whereas sites located further than $1.8 \mathrm{~mm}$ from the capillary outlet recorded only $32 \pm 9 \mu \mathrm{M}$ average maximum cocaine signal. The smooth, exponential appearance of the average cocaine concentration plot obtained from electrodes located less than $200 \mu \mathrm{m}$ from the probe outlet is further testament to the effectiveness of the modified exponential Langmuir model used to convert percent current change to cocaine concentration. The result is the first site specific, direct in vivo measurement of real-time transient cocaine concentration in the brain.

\section{Sensor performance maintained in vivo for at least $180 \mathrm{~min}$}

The in vivo sensing lifetime of the cocaine sensor was determined by measuring the probe response to repeated direct local cocaine infusions in vivo. With the same in vivo experimental design using the capillary anchored probes detailed previously (detailed in Figure 1), the cocaine sensor successfully detects eight individual $1 \mu \mathrm{L}, 250 \mathrm{mM}$ cocaine infusion events delivered at $30 \mathrm{~min}$ increments at a functionalized electrode site located less than $200 \mu \mathrm{m}$ from the capillary outlet (Figure 5a). Due to the baseline SWV drift observed over time (Figure 4a), the percent current change associated with each of the eight direct cocaine infusions was determined relative to the baseline SWV peak height measured immediately prior to each cocaine infusion. This "rolling normalization" procedure is clearly evident in Figure 4a. Each of the eight cocaine infusion events increase the percent current change relative to a newly defined zero baseline (symbolized as a red dot in Figure 5a).

Rolling normalization allows for the continued observation of sensor performance over time and is essential to assessing the effects of in vivo implantation. The average percent current change peak height, normalized to the amplitude of the first infusion (Figure 5b, \pm SEM) reveals that the in vivo detection of direct cocaine infusion does not significantly decrease from the initial infusion response until the $6^{\text {th }}$ infusion (delivered at $\mathrm{t}=180 \mathrm{~min}$, one way ANOVA, $\mathrm{F}(7,15)=7.21, \mathrm{p}<0.01$, Bonferroni post hoc comparison, $\mathrm{p}<0.05$ for infusions 6 through 8 compared to infusion 1). These findings suggest that the aptamer based cocaine sensor is capable of performing high quality in vivo measurements over a period approaching 3 hours. This far exceeds the typical pharmacokinetic lifetime of a single cocaine infusion ( 60 minutes ${ }^{19}, 20$ ), and thus indicates that the novel cocaine sensor will be suitable for acute in vivo experimentation.

Aside from cocaine sensing capabilities, it is important to examine the in vivo baseline drift (Figure $4 \mathrm{a}$ ), the associated right-shift in SWV peak potential (Figure $4 \mathrm{a}$ inset), and the observed decrease of sensor function at time periods after 3 hours in vivo (Figure 5a,b). In vitro testing of sensor lifetime in PBS (using identical SWV data collection conditions detailed for in vivo testing) does not reveal a significant decrease (One way ANOVA, 
$\mathrm{p}>0.05$ ) in the percent current change associated with the repeated detection of $1 \mathrm{mM}$ cocaine over a period of 4.5 hours (normalized to the first detection, Supplementary Figure 2). Furthermore, comparison of the in vitro normalized percent current change to in vivo results (Figure 5b) reveals that in vivo implantation results in a significant decrease (one way ANOVA, $\mathrm{F}(1,4)=12.28, \mathrm{p}<0.05$ ) in cocaine detection after 210 minutes (trending lower at 150 min, Supplementary Figure 2). It is well established that implanted electrodes provoke inflammatory host tissue response which results in microglia polarization and attachment to the probe ${ }^{62,63}$. Scanning electron microscopy images of a representative paraformaldehyde fixed electrode site following explantation from the brain (Figures $4 \mathrm{c}, \mathrm{d}$, additional images provided in Supplementary Figure 3) reveal attachment of biological tissue onto both the gold electrode and silicon shank surfaces. The higher magnification image reveals that the dendritic gold morphology was not altered during the process of probe implantation and explantation (see also Supplementary Figure 3), but that the sensor surface was completely wrapped by biological tissue. Immunohistological staining of explanted devices confirms direct cellular attachment to the probe shank (Figure 5e, blue) as well as the presence of microglial endfeet adhered to both the electrode sites as well as the device substrate (Figure $5 e$, green channel), which is consistent with previous work ${ }^{62,64}$. Interestingly, histology also showed that there is strong presence of $\operatorname{IgG}$ on the electrode sites (Figure 5e, grey channel). $\mathrm{IgG}$ is a plasma protein that is only found in the brain following disruption of the blood brain barrier. This suggests that bleeding and plasma protein leakage may be a significant contributor to the encapsulating biological tissue. The formation of this biological encapsulation likely played a key role in the observed baseline drift and decrease in sensor performance in vivo. Cocaine detection requires a binding event followed by a physical reorientation of the aptamer in space. The direct attachment of biological tissue to the aptamer functionalized electrode surface would likely result in the physical inhibition of aptamer folding in space and a subsequent decrease in cocaine sensitivity. Furthermore, tissue encapsulation commonly increases the impedance at the electrode surface ${ }^{56,65,66}$ which could result in smaller SWV peak amplitudes (baseline drift). Finally, insertion injury could explain the shift in peak potential that accompanied the baseline drift (Figure 4a inset). Previous work has shown the existence of local tissue acidosis associated with the insertion of similar neural recording probes into the brain ${ }^{67}$. Based on the Nernst equation ${ }^{58}$, local changes in $\mathrm{pH}$ result in a subsequent shift in redox peak potential.

The prolonged maintenance of the in vivo cocaine sensor detection capabilities (Figures $5 a, b)$ suggests that initial biological responses (plasma protein adsorption and early inflammatory macrophage and microglia attachment) to the probe surface do not immediately inhibit in vivo probe performance. Instead, it is likely that the increase in tissue encapsulation that occurs over time is responsible for the loss of sensor functionality. Biomaterial strategies aimed at reducing biofouling and controlling inflammatory host tissue responses could be developed to lengthen the lifetime of the sensor ${ }^{68-71}$. It is important to note that there are other possible factors that could contribute to the observed baseline drift and decreased in vivo sensor function. One such example is the possibility that endogenous DNase in the brain degrades the immobilized aptamer on the electrode surface over time. This would result in overall baseline drift and a decrease in cocaine detection current (although the relative proportion of bound aptamer for a given concentration would be 
expected to remain constant) over time as more aptamers are degraded. Modification to the aptamers such as locked nucleic acids (LNAs) and $3^{\prime}$-inverted thymidine will likely to improve the in vivo stability ${ }^{72,73}$. Regardless of the exact mechanism underlying sensor drift and degradation, it is important to note that the newly developed cocaine sensor is the first sensor capable of directly measuring transient cocaine concentration in vivo with high reproducibility for periods approaching 180 minutes.

\section{Direct measurement of intravenous cocaine administration}

Experiments involving the intravenous (I.V.) administration of cocaine were conducted to test the feasibility of the cocaine sensor to measure physiologically relevant transient cocaine activity. For I.V. injection experiments, aptamer functionalized neural recording probes (without the anchored fused silica capillary) were implanted into the rat dorsal striatum using surgical procedures identical to those detailed above. On average $(n=4$ electrodes from two individual rats), cocaine concentration in the dorsal striatum increases immediately following the delivery of a single $2 \mathrm{mg} / \mathrm{kg} \mathrm{I.V}$. cocaine injection into the lateral tail vein (Figure 6, I.V. injection delivered at $\mathrm{t}=0 \mathrm{~min}$, dashed line). The cocaine concentration reaches an average maximum concentration of $14.8 \pm 2.2 \mu \mathrm{M}$ at $6.65 \pm 0.14$ min following IV injection and decreases exponentially over a period of $45 \mathrm{~min}$. This represents the first direct measurement of physiologically relevant transient cocaine concentration in the brain. The pharmacokinetic time course of cocaine exposure following IV injection is in agreement with previous studies in both rodent brain and blood which show that cocaine concentration reaches maximum concentration in approximately $5 \mathrm{~min}$ and exponentially decreases over a period of $60 \mathrm{~min}^{19,20}$. The maximum cocaine concentration observed in the brain with the aptamer-based cocaine sensor is approximately 4.5X higher than the values reported by microdialysis sampling techniques ${ }^{20}$. This finding is not surprising when considering the aforementioned limitations of in vivo microdialysis sampling that result in poor extraction efficiencies.

\section{Electrophysiological recording at aptamer functionalized neural recording electrodes}

Neural recording probes have served as an attractive substrate for the development of the aptamer-based cocaine sensor due to the high spatial and temporal resolution afforded by the existing 16 spatially discrete microelectrode sites. Silicon based neural recording probes have previously demonstrated great success in measuring discrete electrophysiological events in the brain ${ }^{74,75}$. As previously detailed, the electrode modifications performed in this study (dendritic gold deposition and aptamer functionalization) result in an overall decrease in electrode impedance as compared to bare gold electrodes (Figure 2d). As such, we hypothesized that these electrode modifications would not compromise electrophysiological recording capabilities. The aptamer functionalized neural recording probe was indeed capable of measuring high quality sensory-evoked neural activities in the barrel cortex of an isoflurane anesthetized rat (Figure 7). In a representative recording session, three single units were identified on a single aptamer functionalized electrode (Figure 7b). Facial whisker mechanical stimulation increased the firing rates of single-units 1 and 2 (Figure 7c and 7e) and decreased the firing rate of single-unit 3 (Figure 7d). The ability to collect behaviorally relevant electrophysiological recordings reveals an additional sensing modality of the neural recording probe. Dual functional microelectrode arrays 
capable of detecting both electrophysiological and neurochemical signals from multiple sites will greatly advance our ability to understand neural circuitry and the role of neurochemicals in network dynamics.

\section{CONCLUSIONS}

The newly developed electrochemical cocaine sensor was designed as a dendritic gold coated, aptamer functionalized electrode on a silicon-based 16-channel neural recording probe substrate. The technology exhibits robust, reversible in vitro cocaine detection with a calibration response following a modified exponential Langmuir relationship. The cocaine sensor exhibits a $75 \mathrm{x}$ improvement in temporal resolution as compared to microdialysis sampling techniques. Sensors implanted in the rat brain are capable of measuring both direct local cocaine infusion and systemic IV tail vein cocaine injection with high spatial and temporal resolution for durations approaching 2 hours. Novel background subtraction and electrode calibration techniques allow for the removal of baseline drift artifact and direct measurement of in vivo cocaine concentration. Lastly, aptamer functionalized neural recording probes remain capable of measuring high quality electrophysiological neuronal firing events from discrete neurons in vivo. This sensor represents the first technology capable of directly measuring cocaine concentration in the brain and serves as a major advancement in the field of neurochemical sensing. Combining the high spatial and temporal resolution of cocaine detection with the dual functionality of electrophysiological recording further increases the functional impact of the technology and broadens the potential for a wide range of neuroscience research fields. Furthermore, this work details the first fully implantable in vivo aptamer-based sensor. This speaks directly to the in vivo functionality of covalently anchored aptamer and serves to support the use of aptamer-based sensors in the DNase-rich brain environment in future studies.

\section{Supplementary Material}

Refer to Web version on PubMed Central for supplementary material.

\section{Acknowledgments}

The sagittal representation in Figure 1c was adapted from Paxinos and Watson (2007) 50 and the coronal representation in Figure 1d was adapted from an open source drawing of a rat skull provided online by Ivy Livingstone through the BIODIDAC scientific image bank at the University of Ottawa, Ottawa, Canada under the guidelines provided by the Creative Commons Attribution-NonCommerical 4.0 International License (http:// biodidac.bio.uottawa.ca/thumbnails/filedet.htm/File_name/ratt010b/File_type/gif). This work was financially supported by NIH SBIR grants (SBIR 7R43DA035545-02, 1R43DA036264-01, 1R43AA022030-01).

\section{ABBREVIATIONS}

$\begin{array}{ll}\text { SWV } & \text { square wave voltammetry } \\ \text { PBS } & \text { phosphate buffered saline } \\ \text { aCSF } & \text { artificial cerebral spinal fluid } \\ \text { MB } & \text { methylene blue }\end{array}$




$\begin{array}{ll}\text { MCH } & \text { 6-mercapto-1-hexanol } \\ \text { SEM } & \text { standard error of the mean }\end{array}$

\section{References}

1. Giros B, Jaber M, Jones SR, Wightman RM, Caron MG. Nature. 1996; 379:606-612. [PubMed: 8628395]

2. Greco PG, Garris PA. Eur J Pharmacol. 2003; 479:117-125. [PubMed: 14612143]

3. Gulley JM, Zahniser NR. Eur J Pharmacol. 2003; 479:139-152. [PubMed: 14612145]

4. Rocha BA, Fumagalli F, Gainetdinov RR, Jones SR, Ator R, Giros B, Miller GW, Caron MG. Nat Neurosci. 1998; 1:132-137. [PubMed: 10195128]

5. Schmitt KC, Reith MEA. Addiction Reviews 2. 2010; 1187:316-340.

6. Zahniser NR, Larson GA, Gerhardt GA. J Pharmacol Exp Ther. 1999; 289:266-277. [PubMed: 10087014]

7. CBHSQ. Behavioral health trends in the United States: Results from the 2014 National Survey on Drug Use and Health. U. S. D. o. H. a. H. Services, Center for Behavioral Health Statistics and Quality; 2015. HHS Publication No SMA 15-4927, NSDUH Series H-50

8. Carboni E, Imperato A, Perezzani L, Dichiara G. Neuroscience. 1989; 28:653-661. [PubMed: 2710338]

9. Garris PA, Wightman RM. Synapse. 1995; 20:269-279. [PubMed: 7570359]

10. Hollander JA, Carelli RM. J Neurosci. 2007; 27:3535-3539. [PubMed: 17392469]

11. Jones SR, Garris PA, Wightman RM. J Pharmacol Exp Ther. 1995; 274:396-403. [PubMed: 7616424]

12. Wu Q, Reith MEA, Kuhar MJ, Carroll FI, Garris PA. J Neurosci. 2001; 21:6338-6347. [PubMed: 11487657]

13. Maggos CE, Spangler R, Zhou Y, Schlussman SD, Ho A, Kreek MJ. Synapse. 1997; 26:55-61. [PubMed: 9097405]

14. Torres GE, Amara SG. Curr Opin Neurobiol. 2007; 17:304-312. [PubMed: 17509873]

15. Keeler JF, Pretsell DO, Robbins TW. Neuroscience. 2014; 282:156-175. [PubMed: 25062777]

16. Lee FJS, Pei L, Moszczynska A, Vukusic B, Fletcher PJ, Liu F. EMBO J. 2007; 26:2127-2136. [PubMed: 17380124]

17. Maltais S, Cote S, Drolet G, Falardeau S. Prog Neuropsychopharmacol Biol Psychiatry. 2000; 24:1127-1149. [PubMed: 11131177]

18. Weiner DM, Levey AI, Sunahara RK, Niznik HB, Odowd BF, Seeman P, Brann MR. Proc Natl Acad Sci U S A. 1991; 88:1859-1863. [PubMed: 1825729]

19. Bystrowska B, Adamczyk P, Moniczewski A, Zaniewska M, Fuxe K, Filip M. Pharmacol Rep. 2012; 64:1337-1349. [PubMed: 23406744]

20. Bradberry CW, Nobiletti JB, Elsworth JD, Murphy B, Jatlow P, Roth RH. J Neurochem. 1993; 60:1429-1435. [PubMed: 8455033]

21. Borland LM, Shi GY, Yang H, Michael AC. J Neurosci Methods. 2005; 146:149-158. [PubMed: 15975664]

22. Chefer, VI., Thompson, AC., Zapata, A., Shippenberg, TS. Curr Protoc Neurosci. John Wiley \& Sons, Inc; 2001.

23. Jaquins-Gerstl A, Michael AC. J Neurosci Methods. 2009; 183:127-135. [PubMed: 19559724]

24. Khan AS, Michael AC. Trac-Trends in Analytical Chemistry. 2003; 22:503-508.

25. Menacherry S, Hubert W, Justice JB. Anal Chem. 1992; 64:577-583. [PubMed: 1580357]

26. Spiehler VR, Reed D. J Forensic Sci. 1985; 30:1003-1011. [PubMed: 4067533]

27. Tuerk C, Gold L. Science. 1990; 249:505-510. [PubMed: 2200121]

28. Wilson GS, Gifford R. Biosens Bioelectron. 2005; 20:2388-2403. [PubMed: 15854814]

29. Kang D, White RJ, Xia F, Zuo X, Vallee-Belisle A, Plaxco KW. NPG Asia Mater. 2012; 4:e1. 
30. Baker BR, Lai RY, Wood MS, Doctor EH, Heeger AJ, Plaxco KW. J Am Chem Soc. 2006; 128:3138-3139. [PubMed: 16522082]

31. White RJ, Phares N, Lubin AA, Xiao Y, Plaxco KW. Langmuir. 2008; 24:10513-10518. [PubMed: 18690727]

32. Swensen JS, Xiao Y, Ferguson BS, Lubin AA, Lai RY, Heeger AJ, Plaxco KW, Soh HT. J Am Chem Soc. 2009; 131:4262-4266. [PubMed: 19271708]

33. Ferguson BS, Hoggarth DA, Maliniak D, Ploense K, White RJ, Woodward N, Hsieh K, Bonham AJ, Eisenstein M, Kippin TE, Plaxco KW, Soh HT. Sci Transl Med. 2013; 5:213ra165-213ra165.

34. Schoukroun-Barnes LR, Wagan S, White RJ. Anal Chem. 2014; 86:1131-1137. [PubMed: 24377296]

35. Liu J, Wagan S, Dávila Morris M, Taylo J, White RJ. Anal Chem. 2014; 86:11417-11424. [PubMed: 25337781]

36. Xiao Y, Lubin AA, Heeger AJ, Plaxco KW. Angew Chem. 2005; 117:5592-5595.

37. Xiao Y, Piorek BD, Plaxco KW, Heeger AJ. J Am Chem Soc. 2005; 127:17990-17991. [PubMed: 16366535]

38. Lai RY, Plaxco KW, Heeger AJ. Anal Chem. 2007; 79:229-233. [PubMed: 17194144]

39. Macazo FC, Karpel RL, White RJ. Langmuir. 2015; 31:868-875. [PubMed: 25517392]

40. Liao W, Cui XT. Biosens Bioelectron. 2007; 23:218-224. [PubMed: 17512185]

41. Liao W, Randall BA, Alba NA, Cui XT. Anal Bioanal Chem. 2008; 392:861-864. [PubMed: 18784918]

42. Luo X, Lee I, Huang J, Yun M, Cui XT. Chem Commun. 2011; 47:6368-6370.

43. Obien MEJ, Deligkaris K, Bullmann T, Bakkum DJ, Frey U. Front Neurosci. 2015; 8

44. Hochberg LR, Serruya MD, Friehs GM, Mukand JA, Saleh M, Caplan AH, Branner A, Chen D, Penn RD, Donoghue JP. Nature. 2006; 442:164-171. [PubMed: 16838014]

45. Csicsvari J, Henze DA, Jamieson B, Harris KD, Sirota A, Barthó P, Wise KD, Buzsáki G. J Neurophysiol. 2003; 90:1314-1323. [PubMed: 12904510]

46. Cui X, Martin DC. Sensors and Actuators A: Physical. 2003; 103:384-394.

47. Xiao Y, Lai RY, Plaxco KW. Nat Protocols. 2007; 2:2875-2880. [PubMed: 18007622]

48. Lao R, Song S, Wu H, Wang L, Zhang Z, He L, Fan C. Anal Chem. 2005; 77:6475-6480. [PubMed: 16194115]

49. Pellegrino, LJ., Pellegrino, AS., Cushman, AJ. A Stereotaxic Atlas of the Rat Brain. Plenum Press; New York, NY: 1979.

50. Paxinos, G., Watson, C. The rat brain in stereotaxic coordinates. Academic Press; London, UK: 2007.

51. Krupa DJ, Brisben AJ, Nicolelis MA. J Neurosci Methods. 2001; 104:199-208. [PubMed: 11164246]

52. Wagenaar DA, Potter SM. J Neurosci Methods. 2002; 120:113-120. [PubMed: 12385761]

53. Ludwig KA, Uram JD, Yang J, Martin DC, Kipke DR. J Neural Eng. 2006; 3:59-70. [PubMed: 16510943]

54. Shoham S, Fellows MR, Normann RA. J Neurosci Methods. 2003; 127:111-122. [PubMed: 12906941]

55. Weaver CL, LaRosa JM, Luo X, Cui XT. ACS Nano. 2014; 8:1834-1843. [PubMed: 24428340]

56. Kozai TDY, Jaquins-Gerstl AS, Vazquez AL, Michael AC, Cui XT. ACS Chem Neurosci. 2015; 6:48-67. [PubMed: 25546652]

57. Kozai TDY, Du Z, Gugel ZV, Smith MA, Chase SM, Bodily LM, Caparosa EM, Friedlander RM, Cui XT. J Neurosci Methods. 2015; 242:15-40. [PubMed: 25542351]

58. Bard, AJ., Faulkner, LR. Electrochemical Methods: Fundamentals and Applications. 2. John Wiley \& Sons, Inc.; Hoboken, NJ: 2001.

59. Cekan P, Jonsson EÖ, Sigurdsson ST. Nucleic Acids Res. 2009; 37:3990-3995. [PubMed: 19406921]

60. Ricci F, Lai RY, Heeger AJ, Plaxco KW, Sumner JJ. Langmuir. 2007; 23:6827-6834. [PubMed: 17488132] 
61. Grant PG, Lemke SL, Dwyer MR, Phillips TD. Langmuir. 1998; 14:4292-4299.

62. Kozai TDY, Vazquez AL, Weaver CL, Kim SG, Cui XT. Journal of Neural Engineering. 2012; 9:066001. [PubMed: 23075490]

63. Biran R, Martin DC, Tresco PA. Exp Neurol. 2005; 195:115-126. [PubMed: 16045910]

64. Eles JR, Vazquez AL, Snyder NR, Lagenaur CF, Murphy MC, Kozai TDY, Cui XT. Biomaterials. 2017; 113:279-292. [PubMed: 27837661]

65. Williams DF. Biomaterials. 2008; 29:2941-2953. [PubMed: 18440630]

66. Ersen A, Elkabes S, Freedman DS, Sahin M. Journal of Neural Engineering. 2015; 12:016019. [PubMed: 25605679]

67. Johnson MD, Kao OE, Kipke DR. J Neurosci Methods. 2007; 160:276-287. [PubMed: 17084461]

68. Azemi E, Lagenaur CF, Cui XT. Biomaterials. 2011; 32:681-692. [PubMed: 20933270]

69. Kozai TD, Jaquins-Gerstl AS, Vazquez AL, Michael AC, Cui XT. ACS Chem Neurosci. 2015; 6:48-67. [PubMed: 25546652]

70. Kozai TD, Jaquins-Gerstl AS, Vazquez AL, Michael AC, Cui XT. Biomaterials. 2016; 87:157-169. [PubMed: 26923363]

71. Banerjee I, Pangule RC, Kane RS. Adv Mater. 2011; 23:690-718. [PubMed: 20886559]

72. Schmidt KS, Borkowski S, Kurreck J, Stephens AW, Bald R, Hecht M, Friebe M, Dinkelborg L, Erdmann VA. Nucleic Acids Res. 2004; 32:5757-5765. [PubMed: 15509871]

73. Takei Y, Kadomatsu K, Itoh H, Sato W, Nakazawa K, Kubota S, Muramatsu T. J Biol Chem. 2002; 277:23800-23806. [PubMed: 11959856]

74. Kozai TD, Li X, Bodily LM, Caparosa EM, Zenonos GA, Carlisle DL, Friedlander RM, Cui XT. Biomaterials. 2014; 35:9620-9634. [PubMed: 25176060]

75. Du ZJ, Luo X, Weaver C, Cui XT. J Mater Chem C Mater Opt Electron Devices. 2015; 3:65156524. [PubMed: 26491540] 
- First ever in vivo sensor for directly measuring cocaine concentration in the brain

- $\quad$ DNA aptamer functionalized single shank, silicon-based neural recording probe

- Exhibits a $75 x$ increase in temporal resolution as compared to microdialysis

- Dual functionality as a cocaine sensor and electrophysiological recording electrode 
롤

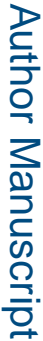

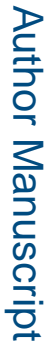

c)



a)

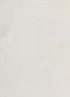

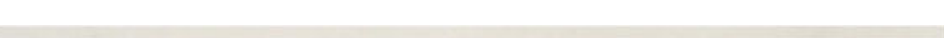



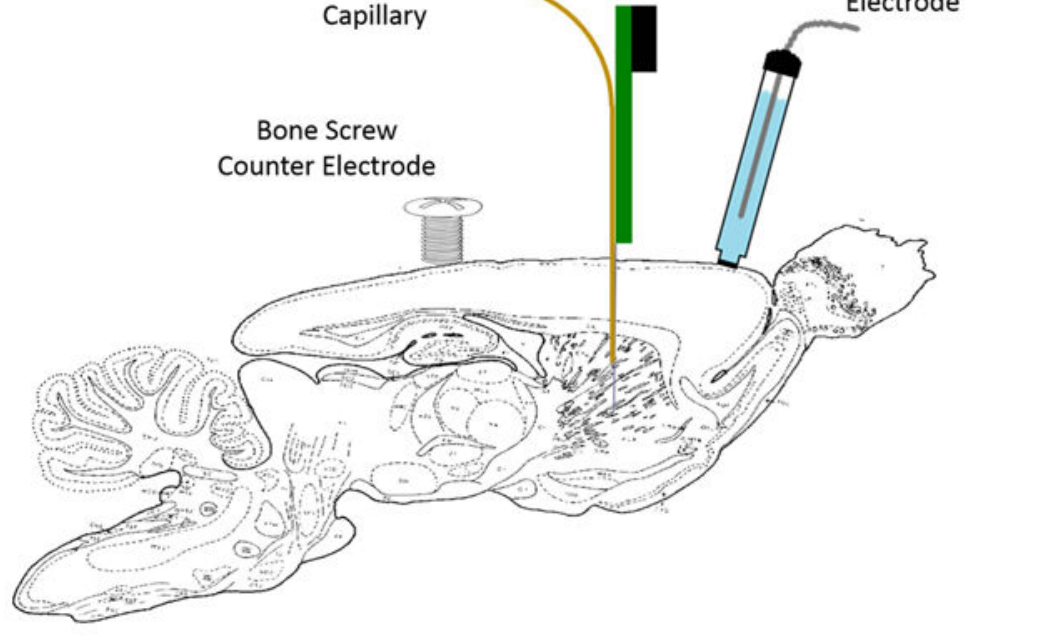

b)


Figure 1.

J Mater Chem B Mater Biol Med. Author manuscript; available in PMC 2018 April 07. 


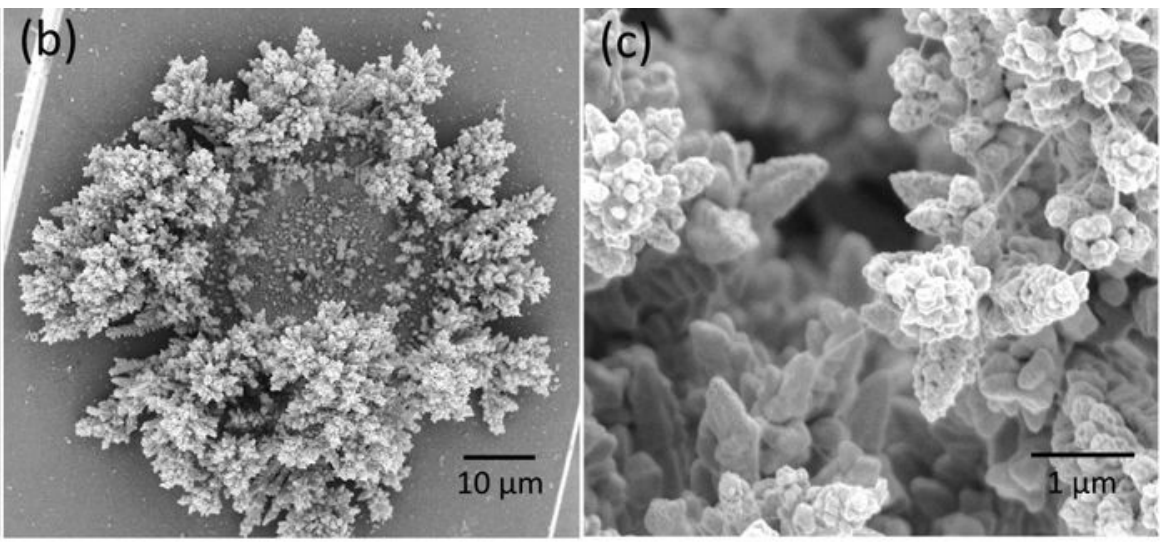

(e)

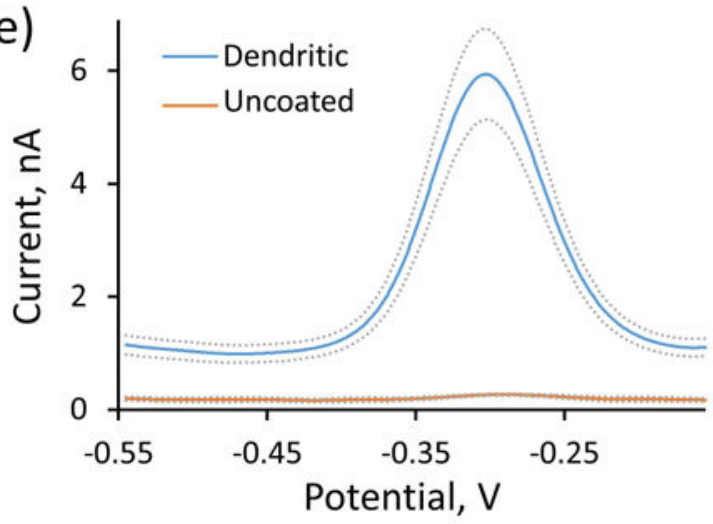

Figure 2. 
a)

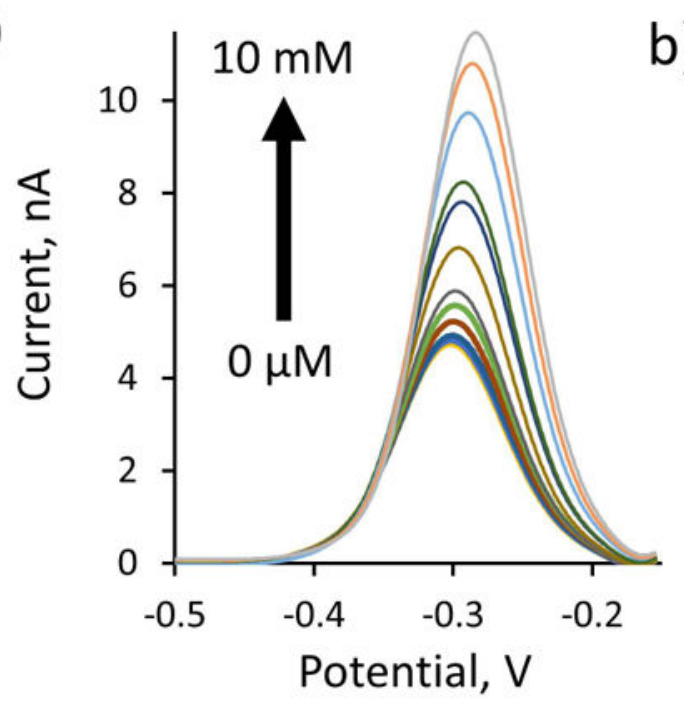

c)

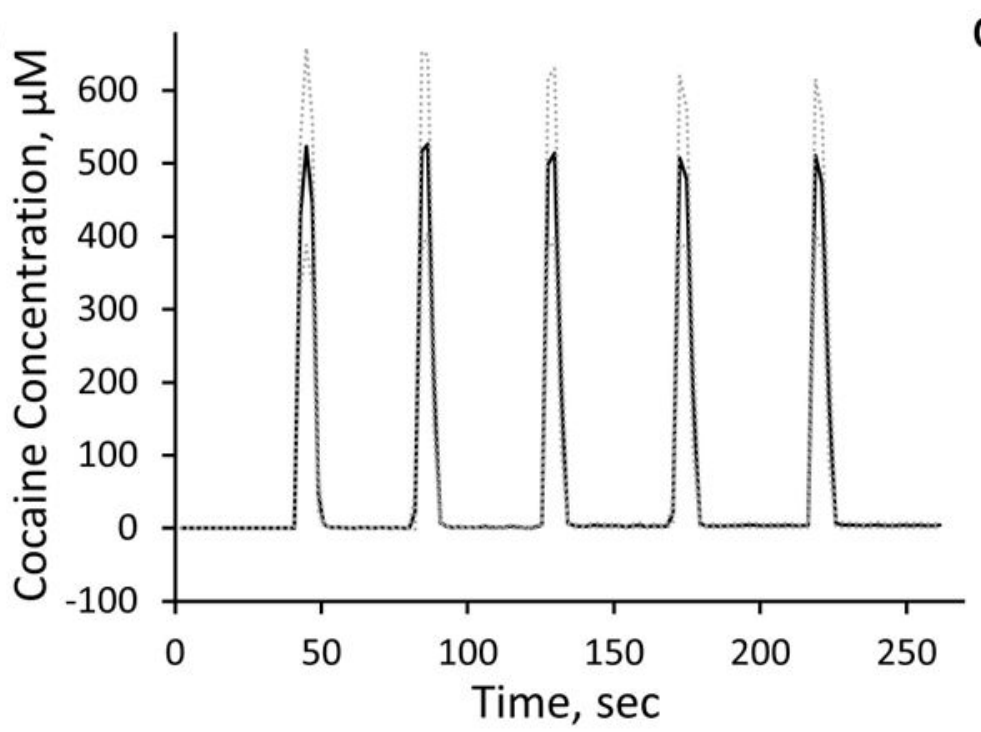

b)

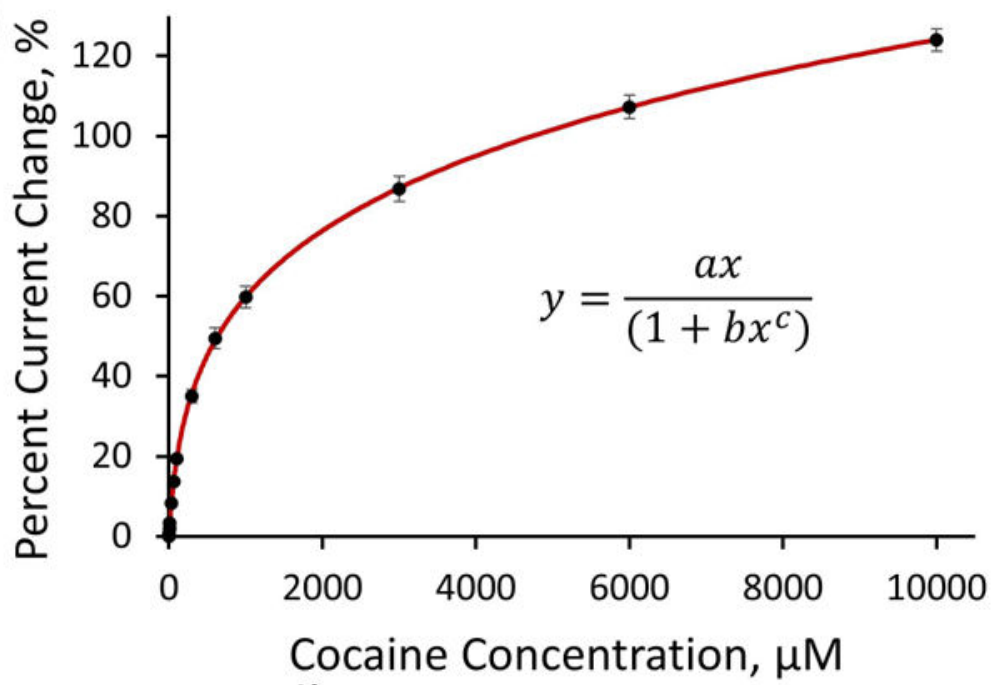

d)

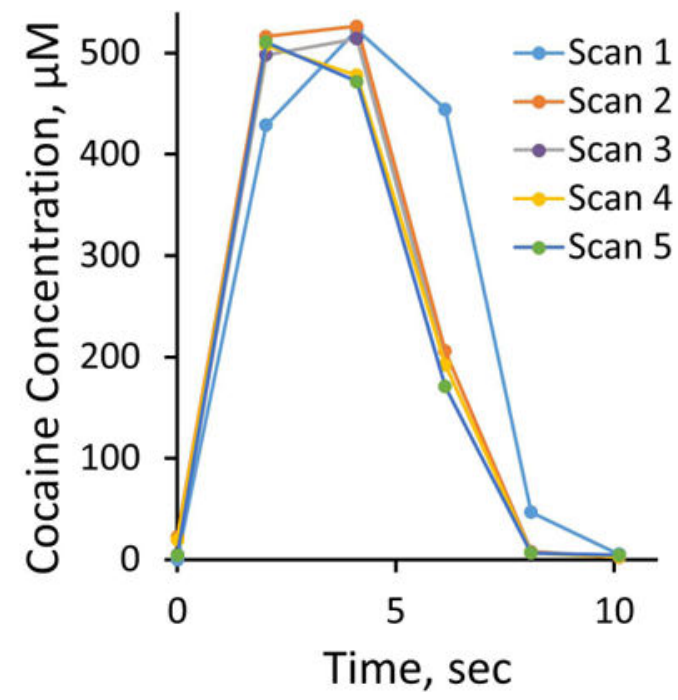

Figure 3. 



Figure 4. 
a)

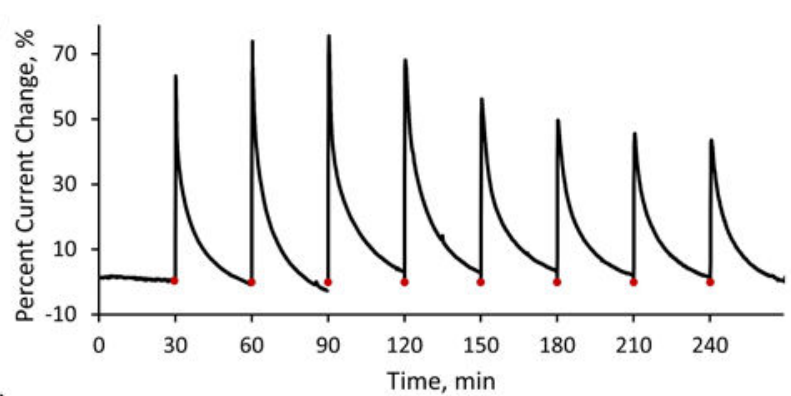

b)



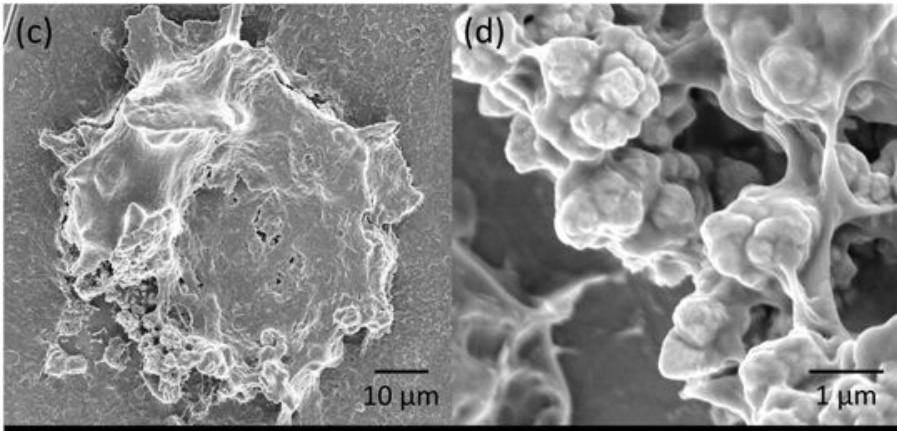

(e)

/ Microglia / IgG (plasma protein)

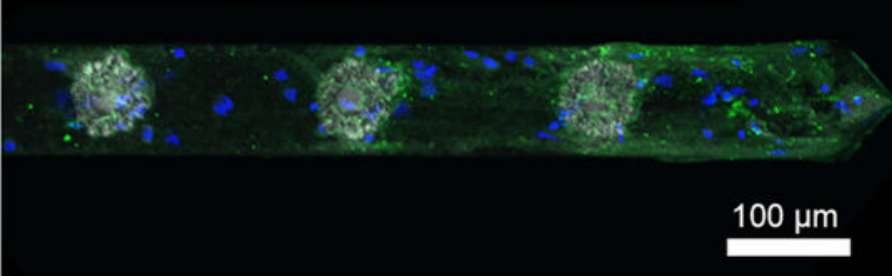

Figure 5. 


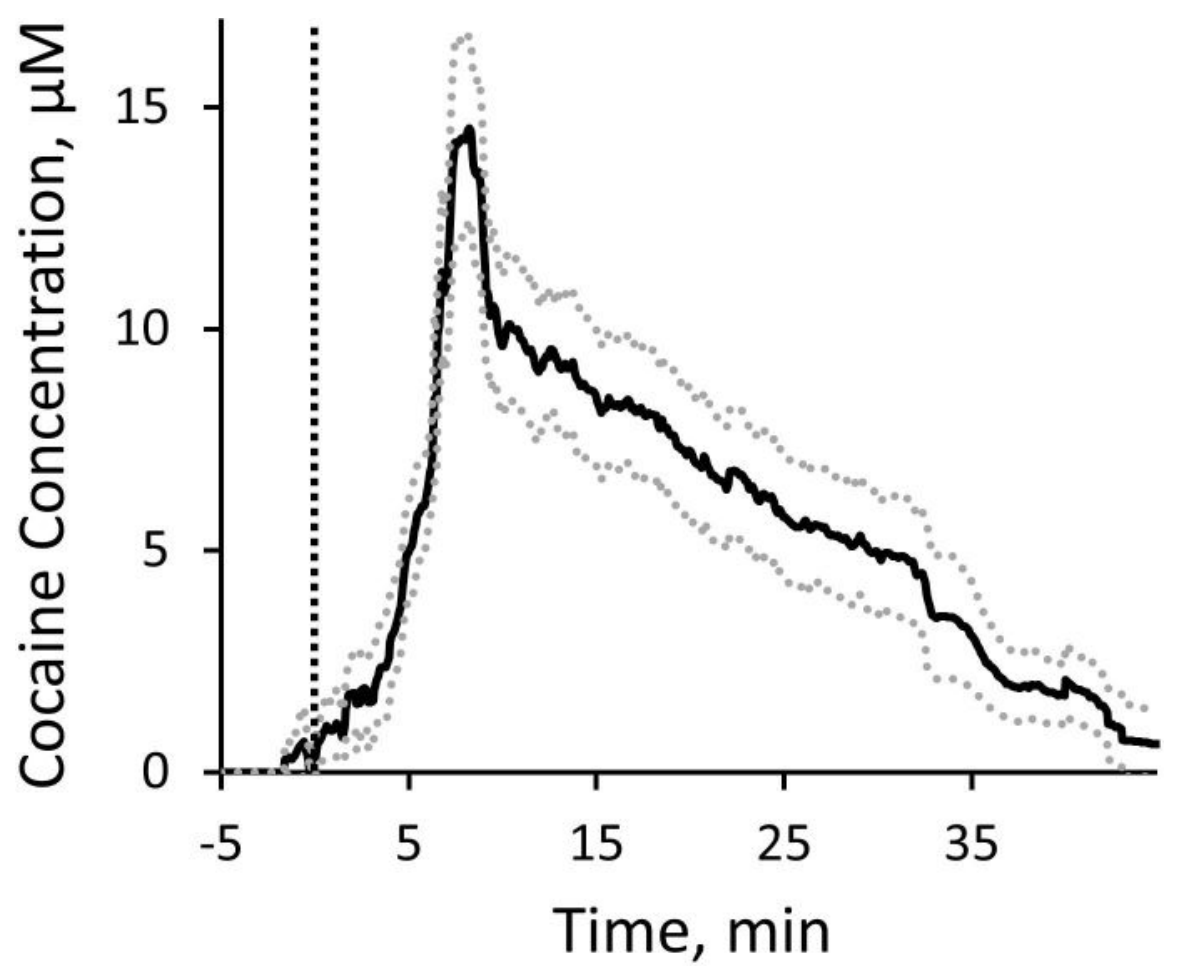

Figure 6. 

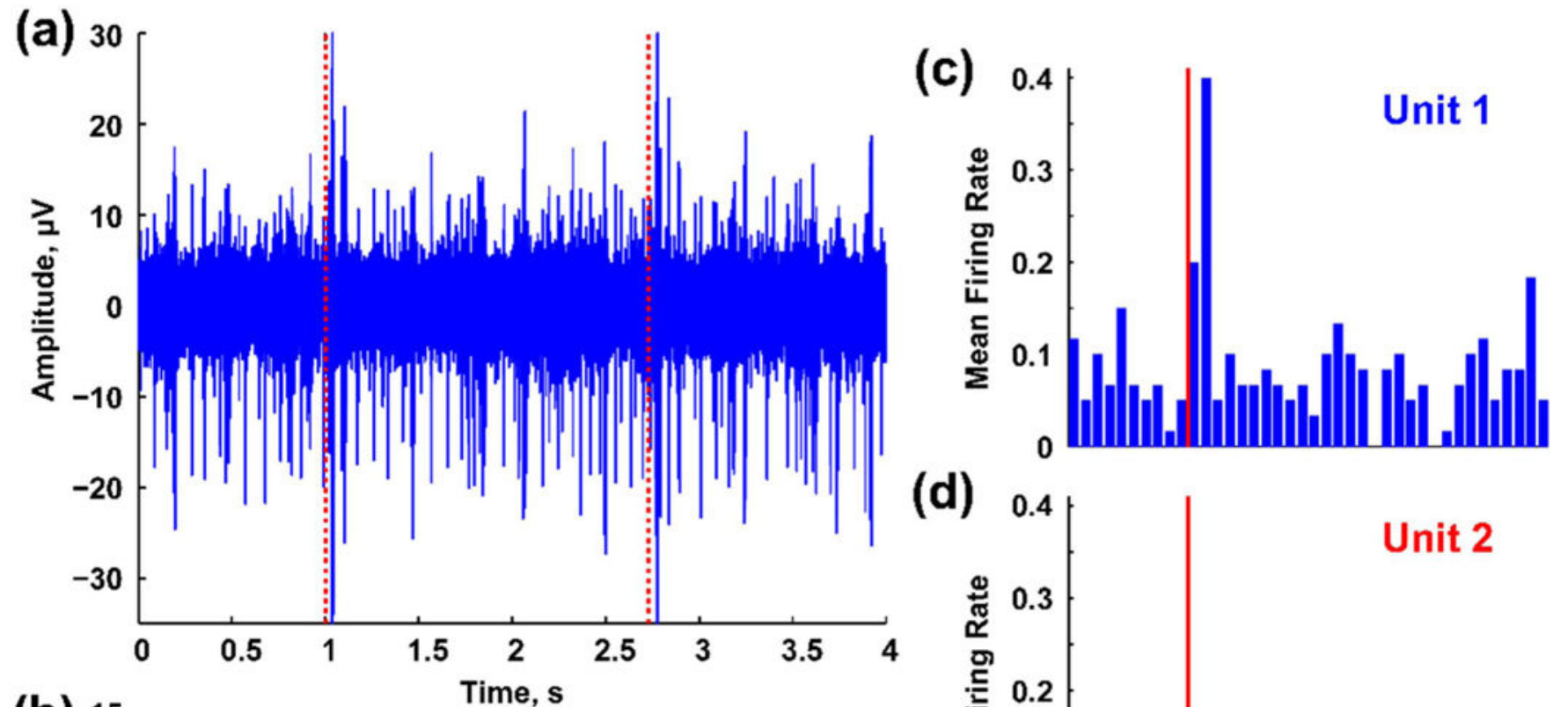



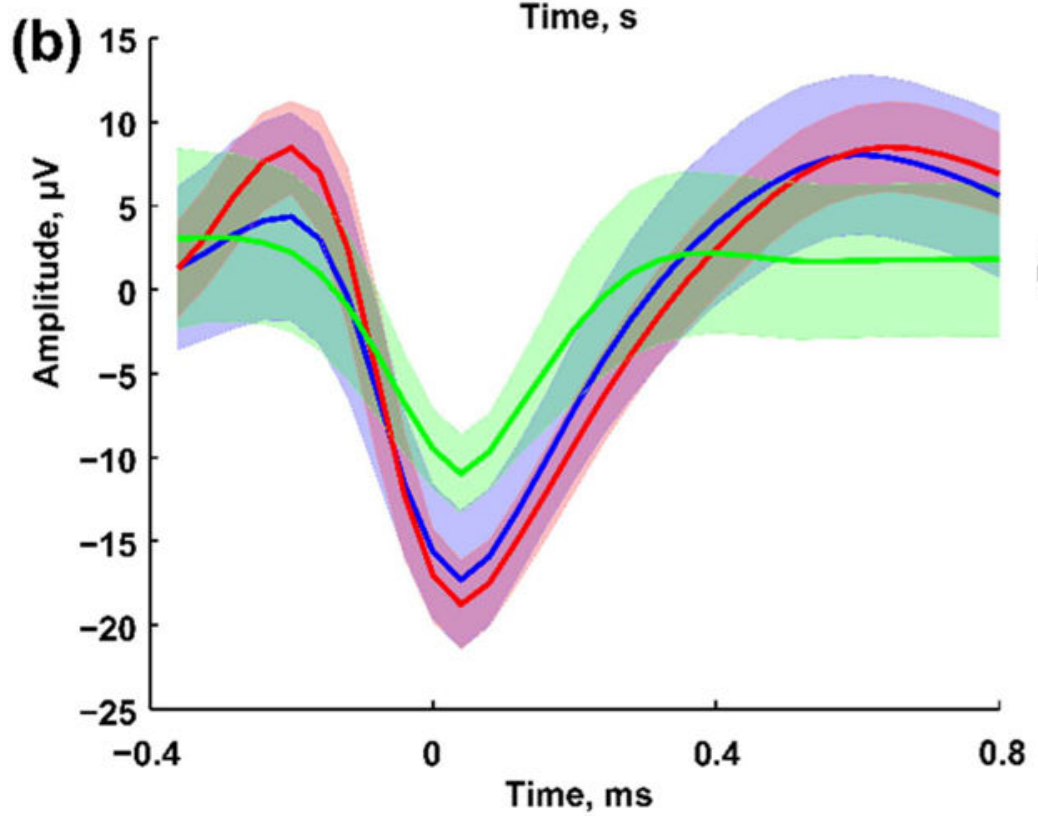

(d)

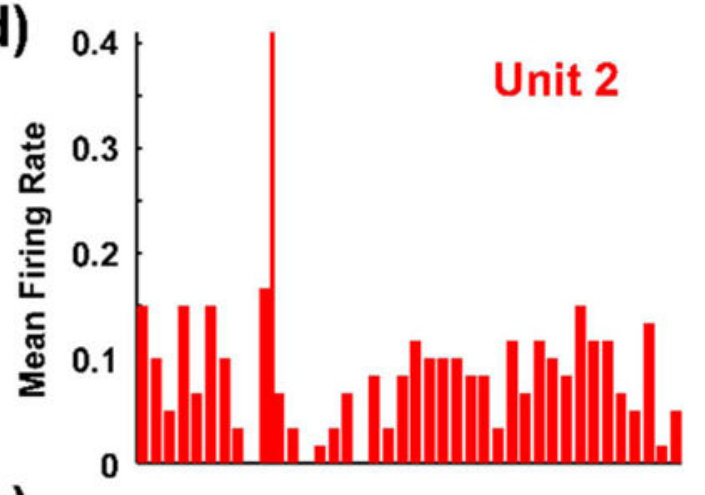



(e)

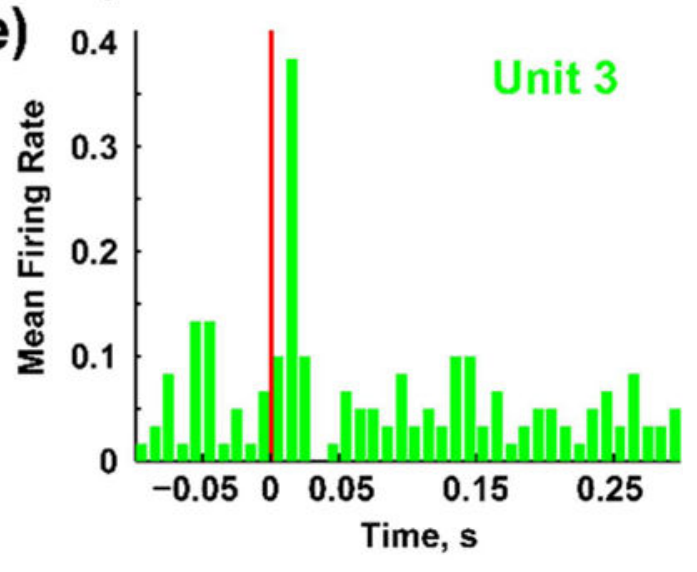

Figure 7. 